Pacific Journal of Mathematic 


\section{A NEW PROOF OF THE MAXIMUM PRINCIPLE FOR DOUBLY-HARMONIC FUNCTIONS}

\section{H. B. Mann, Josephine Mitchell and Lowell Schoenfeld}

Let $f$ be a real-valued Lebesque integrable function on a domain $\Omega$ in Euclidean space $E_{2 m}$, and let $f$ be doubly-harmonic on $\Omega$ so that it satisfies

$$
\frac{\partial^{2} f}{\partial x_{2 k-1}^{2}}+\frac{\partial^{2} f}{\partial x_{2 k}^{2}}=0 \quad \text { for } k=1,2, \cdots, m .
$$

In this paper, a new proof of the maximum principle is given for nonconstant functions $f$ satisfying the preceding conditions.

The proof depends on the fact that the associated forms

$$
\varphi_{p}(H ; f)=\sum_{r_{1}+\cdots+r_{n}=p} \frac{h_{1}^{r_{1}} \cdots h_{n}^{r_{n}}}{r_{1} ! \cdots r_{n} !}\left(\frac{\partial^{p} f}{\partial x_{1}^{r_{1}} \cdots \partial x_{n}^{r_{n}}}\right)_{x=A},
$$

where $A \in \Omega$, are either indefinite or identically 0 for each $p \geqq 1$. The authors previously proved this under weaker hypotheses on $f$, but the proof used the strong form of the maximum principle for solutions of linear elliptic partial differential equations of the second order with constant coefficients. By means of the theory of distributions, the authors now prove that the $\varphi_{p}(H ; f)$ have the stated property without using the maximum principle. Consequently, they obtain a new proof of this principle.

1. Introduction. We say that $f$ is doubly-harmonic on a domain $\Omega \subset E_{2 m}$ if it is a real-valued function defined on $\Omega$ such that the equations

$$
\frac{\partial^{2} f}{\partial x_{2 k-1}^{2}}+\frac{\partial^{2} f}{\partial x_{2 k}^{2}}=0, \quad k=1,2, \cdots, m
$$

hold for all $\left(x_{1}, \cdots, x_{2 m}\right) \in \Omega$. Such a function $f$ is necessarily harmonic on $\Omega$ since on adding the $m$ equations (1) we see that $f$ satisfies the Laplace equation

$$
\frac{\partial^{2} f}{\partial x_{1}^{2}}+\frac{\partial^{2} f}{\partial x_{2}^{2}}+\cdots+\frac{\partial^{2} f}{\partial x_{2 m-1}^{2}}+\frac{\partial^{2} f}{\partial x_{2 m}^{2}}=0 .
$$

Moreover, the class of doubly-harmonic functions contains each function that is the real part of a function of $m$ complex variables which is holomorphic on $\Omega$; this can be seen from the Cauchy-Riemann equations applied to each complex variable $x_{2 k-1}+i x_{2 k}$ separately. Obviously, if $m=1$, the class of doubly-harmonic functions coincides with the class of harmonic functions.

2. Two lemmas. Throughout, we use the notation of our earlier 
paper [3]. In particular, $\varphi_{p}(H ; f)$, which depends also on a point $A \in \Omega$, is defined in (2) of [3], and $\theta=(0, \cdots, 0)$ denotes the origin.

LEMMA 1. If $f$ is a homogeneous polynomial of degree $q$ defined on $E_{n}$ and if $A=\theta$, then

$$
\varphi_{p}(H ; f)= \begin{cases}f(H) & \text { if } p=q \\ 0 & \text { if } p \neq q .\end{cases}
$$

Proof. First, consider the special case

$$
f_{0}(X)=c x_{1}^{s_{1}} \cdots x_{n}^{s_{n}}
$$

where $s_{1}+\cdots+s_{n}=q$. On applying the definition of $D_{X}^{|R|}$ in (1) of [3], we get

$$
D_{X}^{|R|} f_{0}=r_{1} ! \cdots r_{n} ! c\left(\begin{array}{c}
s_{1} \\
r_{1}
\end{array}\right) \cdots\left(\begin{array}{c}
s_{n} \\
r_{n}
\end{array}\right) x_{1}^{s_{1}-r_{1}} \cdots x_{n}^{s_{n}-r_{n}}
$$

so that $D_{X}^{|R|} f_{0}=0$ if $r_{j}>s_{j}$ for some $j$. And if $r_{j}<s_{j}$ for some $j$, then $\left(D_{X}^{|R|} f_{0}\right)_{X=\theta}=0$. In the remaining case in which $r_{j}=s_{j}$ for all $j$, i.e., $R=S$, we have $D_{X}^{|R|} f_{0}=S ! c$. Hence, from (2) of [3], we obtain $\varphi_{p}\left(H ; f_{0}\right)=0$ if $p \neq q$ and

$$
\varphi_{q}\left(H ; f_{0}\right)=\frac{1}{S !} h_{1}^{s_{1}} \cdots h_{n}^{s_{n}} S ! c=f_{0}(H) \text {. }
$$

Second, consider the case of a general homogeneous polynomial $f$ of degree $q$. Then $f$ is a linear combination of terms of the kind $f_{0}$. Since $\varphi_{q}(H ; f)$ is linear in the last argument, the result for $f$ follows from the result for each of the $f_{0}$.

LeMma 2. If $P(x, y)$ is a harmonic polynomial, then it is either a constant or is an indefinite function.

Proof. Suppose $P$ is not a constant so that it is of exact degree $p \geqq 1$. Then

$$
P(x, y)=J_{p}(x, y)+J_{p-1}(x, y)+\cdots+J_{0}(x, y),
$$

where $J_{k}(x, y)$ is a homogeneous polynomial of degree $k$ and $J_{p}$ is not identically 0 . If $p=1$, then $P$ is clearly indefinite. We therefore assume that $p \geqq 2$. Then

$$
0=\left(\frac{\partial^{2}}{\partial x^{2}}+\frac{\partial^{2}}{\partial y^{2}}\right) P(x, y)=I_{p-2}(x, y)+I_{p-3}(x, y)+\cdots+I_{0}(x, y)
$$

where, for $0 \leqq k \leqq p-2$, 


$$
I_{k}(x, y)=\left(\frac{\partial^{2}}{\partial x^{2}}+\frac{\partial^{2}}{\partial y^{2}}\right) J_{k+2}(x, y)
$$

is a homogeneous form of degree $k$. If not all $I_{k}$ are identically 0 , then there is a largest index $r \geqq 0$ such that $I_{r}$ is not identically 0 . Then

$$
0=I_{r}(x, y)+I_{r-1}(x, y)+\cdots+I_{0}(x, y)
$$

with $I_{r}(a, b) \neq 0$ for some $a, b$. Hence, for all real $t$,

$$
\begin{aligned}
0 & =I_{r}(t a, t b)+I_{r-1}(t a, t b)+\cdots+I_{0}(t a, t b) \\
& =t^{r} I_{r}(a, b)+t^{r-1} I_{r-1}(a, b)+\cdots+I_{0}(a, b) .
\end{aligned}
$$

Since $I_{r}(a, b) \neq 0$, this equation can hold for at most $r \leqq p-2$ values of $t$ and we have a contradiction. Consequently, each $I_{k}$ is identically 0 so that each $J_{j}$ is harmonic. Since $J_{p}$ is harmonic, we can apply Mann's result [2] (with $A=\theta$ ) to deduce that $\varphi_{p}\left(h, k ; J_{p}\right)$ is either an indefinite form in $h, k$ or is a constant (actually 0). By Lemma 1 above, $\varphi_{p}\left(h, k ; J_{p}\right)$ is just $J_{p}(h, k)$ which has exact degree $p \geqq 2$; consequently, it is not a constant and hence is indefinite. Therefore, for suitable $h_{0}, k_{0}$ and $h_{1}, k_{1}$ we have $J_{p}\left(h_{0}, k_{0}\right)<0<J_{p}\left(h_{1}, k_{1}\right)$. Hence

$$
P\left(t h_{0}, t k_{0}\right)=t^{p} J_{p}\left(h_{0}, k_{0}\right)+t^{p-1} J_{p-1}\left(h_{0}, k_{0}\right)+\cdots+J_{0}\left(h_{0}, k_{0}\right)<0
$$

if $t$ is positive and large enough. Likewise, $P\left(t h_{1}, t k_{1}\right)>0$ if $t$ is positive and large enough. Thus $P$ is indefinite.

3. The main results. We begin with the following result which extends Theorem 2 of [3].

THEOREM 1. If $f$ is a Lebesgue integrable doubly-harmonic function on a domain $\Omega \subset E_{2 m}$, then $f$ is analytic on $\Omega$. And if $A \in \Omega$, then the forms $\varphi_{p}(H ; f)$ are doubly-harmonic functions on $E_{2 m}$ such that for each $p \geqq 1$ either the form is indefinite or is identically zero.

Proof. As remarked earlier, $f$ satisfies the Laplace equation (2). Since it is integrable, the expression $\int_{\Omega} f(X) \psi(X) d X$, for a test function $\psi$, defines a distribution as we remarked in the proof of Theorem 1 of [3]. This distribution also satisfies the elliptic equation (2). By Corollary 4.4.1 on p. 114 of Hörmander [1], it follows that the function $f$ is analytic on $\Omega$.

Consequently, the forms $\varphi_{p}(H ; f)$ are defined; and by the corollary of the lemma in [3], these forms are doubly-harmonic on $E_{2 m}$. Suppose that for some $p \geqq 1, \varphi_{p}(H ; f)$ is not indefinite; then we may as- 
sume it is always nonnegative. If we fix $h_{3}, \cdots, h_{2 m}$ then $\varphi_{p}(H ; f)$ becomes a harmonic polynomial in $h_{1}, h_{2}$. By Lemma 2 , it is either indefinite or is independent of $h_{1}, h_{2}$; since it is nonnegative, it cannot be indefinite and hence must be independent of $h_{1}, h_{2}$. That is, $\varphi_{p}(H ; f)$ depends only $\left(h_{3}, \cdots, h_{2 m}\right)$. Similarly, it is independent of $h_{3}, h_{4}$ so that it depends only on $\left(h_{5}, \cdots, h_{2 m}\right)$. Continuing in this way, we see that $\varphi_{p}(H ; f)$ depends only on $\left(h_{2 m-1}, h_{2 m}\right)$; finally, it is independent of $\left(h_{2 m-1}, h_{2 m}\right)$ as well so that $\varphi_{p}(H ; f)$ is actually a constant. This constant is $\varphi_{p}(\theta ; f)=0$ since $p \geqq 1$. This completes the proof.

THEOREM 2. If $f$ is a nonconstant Lebesgue integrable doublyharmonic function on a domain $\Omega \subset E_{2 m}$, then it does not assume a maximum at a point in $\Omega$.

Proof. Suppose, on the contrary, that $f$ assumes a maximum at a point $A \in \Omega$. The preceding theorem shows that $f$ is analytic in $\Omega$; it therefore has a Taylor expansion about $A$ given by

$$
f(X)=\sum_{r=0}^{\infty} \varphi_{r}(X-A ; f) .
$$

Since $f$ is not a constant, there is some integer $p \geqq 1$ such that $\varphi_{r}(H ; f)$ is identically 0 for each $r=1,2, \cdots, p-1$, but $\varphi_{p}(H ; f)$ is not identically 0 . Inasmuch as the previous theorem shows that $\varphi_{p}(H ; f)$ is indefinite, there is some $C=\left(c_{1}, \cdots, c_{2 m}\right)$ such that $\varphi_{p}(C ; f)>0$. Then $C \neq \theta$ so that $c \equiv\|C\|>0$. Applying Taylor's theorem with remainder, we have for all $B$ in some neighborhood of $A$

$$
f(B)-f(A)=\sum_{r=1}^{p-1} \varphi_{r}(B-A ; f)+\varphi_{p}^{*}(B-A ; f)=\varphi_{p}^{*}(B-A ; f)
$$

where, on putting $n=2 m$,

$$
\varphi_{p}^{*}(H ; f)=\sum_{|R|=q} \frac{1}{R !} h_{1}^{r_{1}} \cdots h_{n}^{r_{n}}\left(D_{X}^{|R|} f\right)_{X=D}
$$

and $D=A+\vartheta(B-A), 0<\vartheta<1$, is a suitable point on the line segment joining $A$ and $B$. If we define

$$
\varepsilon=\frac{1}{2} \cdot \frac{p !}{(n c)^{p}} \varphi_{p}(C ; f),
$$

then there is a $\delta>0$ such that, for all $R$ with $|R|=p$,

$$
\left|\left(D_{X}^{|R|} f\right)_{X=Y}-\left(D_{X}^{|R|} f\right)_{X=A}\right|<\varepsilon
$$

whenever $\|Y-A\|<\delta$. Consequently, on taking $B=A+\lambda C$ and $0<\lambda<\delta / c$, we find 


$$
\begin{aligned}
\mid \varphi_{p}^{*}(\lambda C ; f) & -\varphi_{p}(\lambda C ; f) \mid \leqq \varepsilon \sum_{|R|=p} \frac{1}{R !}\left(\lambda\left|c_{1}\right|\right)^{r_{1}} \cdots\left(\lambda\left|c_{n}\right|\right)^{r_{n}} \\
& \leqq \frac{\varepsilon}{p !}\left(\lambda\left|c_{1}\right|+\cdots+\lambda\left|c_{n}\right|\right)^{p} \leqq \frac{\varepsilon}{p !}(\lambda n c)^{p}=\frac{1}{2} \lambda^{p} \varphi_{p}(C ; f) .
\end{aligned}
$$

Since $f(A)$ is maximal,

$$
\begin{aligned}
0 \geqq f(A+\lambda C)-f(A) & =\varphi_{p}^{*}(\lambda C ; f) \geqq \varphi_{p}(\lambda C ; f)-\frac{1}{2} \lambda^{p} \varphi_{p}(C ; f) \\
& =\lambda^{p} \varphi_{p}(C ; f)-\frac{1}{2} \lambda^{p} \varphi_{p}(C ; f) \\
& =\frac{1}{2} \lambda^{p} \varphi_{p}(C ; f)>0
\end{aligned}
$$

for all sufficiently small $\lambda>0$. This contradiction proves the theorem.

\section{REFERENCES}

1. Lars Hörmander, Linear partial differential operators, Die Grundlehren der Mathematischen Wissenschaften 116 (1963), Springer-Verlag, Berlin.

2. H. B. Mann, On a property of harmonic functions, Amer. Math. Monthly 66 (1959), 414.

3. H. B. Mann, Josephine Mitchell, and Lowell Schoenfeld, Properties of differential forms in $n$ real variables, Pacific J. Math. 21 (1967), 525-529.

Received September 12, 1967. Sponsored by the Mathematics Research Center, United States Army, Madison, Wisconsin, under Contract No. DA-31-124-ARO-D-462.

Mathematics Research Center

MADISON, WISCONSIN,

The Pennsylvania State University

State College, Pennsylvania

The Pennsylvania State University

State College, Pennsylvania 



\section{PACIFIC JOURNAL OF MATHEMATICS}

\section{EDITORS}

\section{H. ROYDEN}

Stanford University

Stanford, California

\section{J. Dugundu}

Department of Mathematics University of Southern California Los Angeles, California 90007

RICHARD ARENS

University of California Los Angeles, California 90024

ASSOCIATE EDITORS
E. F. Beckenbach
B. H. NEUMANN
F. WoLF
K. YosidA

\section{SUPPORTING INSTITUTIONS}

\author{
UNIVERSITY OF BRITISH COLUMBIA \\ CALIFORNIA INSTITUTE OF TECHNOLOGY \\ UNIVERSITY OF CALIFORNIA \\ MONTANA STATE UNIVERSITY \\ UNIVERSITY OF NEVADA \\ NEW MEXICO STATE UNIVERSITY \\ OREGON STATE UNIVERSITY \\ UNIVERSITY OF OREGON \\ OSAKA UNIVERSITY \\ UNIVERSITY OF SOUTHERN CALIFORNIA
}

STANFORD UNIVERSITY

UNIVERSITY OF TOKYO

UNIVERSITY OF UTAH

WASHINGTON STATE UNIVERSITY

UNIVERSITY OF WASHINGTON

AMERICAN MATHEMATICAL SOCIETY
CHEVRON RESEARCH CORPORATION
TRW SYSTEMS

AMERICAN MATHEMATICAL SOCIETY

TRW SYSTEMS

NAVAL WEAPONS CENTER

Mathematical papers intended for publication in the Pacific Journal of Mathematics should be in typed form or offset-reproduced, double spaced with large margins. Underline Greek letters in red, German in green, and script in blue. The first paragraph or two must be capable of being used separately as a synopsis of the entire paper. It should not contain references to the bibliography. Manuscripts, in duplicate if possible, may be sent to any one of the four editors. All other communications to the editors should be addressed to the managing editor, Richard Arens, University of California, Los Angeles, California 90024.

Each author of each article receives 50 reprints free of charge; additional copies may be obtained at cost in multiples of 50 .

The Pacific Journal of Mathematics is published monthly. Effective with Volume 16 the price per volume (3 numbers) is $\$ 8.00$; single issues, $\$ 3.00$. Special price for current issues to individual faculty members of supporting institutions and to individual members of the American Mathematical Society: $\$ 4.00$ per volume; single issues $\$ 1.50$. Back numbers are available.

Subscriptions, orders for back numbers, and changes of address should be sent to Pacific Journal of Mathematics, 103 Highland Boulevard, Berkeley 8, California.

Printed at Kokusai Bunken Insatsusha (International Academic Printing Co., Ltd.), 7-17, Fujimi 2-chome, Chiyoda-ku, Tokyo, Japan.

PUBLISHED BY PACIFIC JOURNAL OF MATHEMATICS, A NON-PROFIT CORPORATION

The Supporting Institutions listed above contribute to the cost of publication of this Journal, but they are not owners of publishers and have no responsibility for its content or policies. 


\section{Pacific Journal of Mathematics \\ Vol. 27, No. 3}

March, 1968

Charles A. Akemann, Invariant subspaces of $C(G) \ldots \ldots \ldots \ldots \ldots \ldots . \ldots 41$

Dan Amir and Zvi Ziegler, Generalized convexity cones and their duals ... . 425

Raymond Balbes, On ( $J, M, \mathrm{~m})$-extensions of order sums of distributive

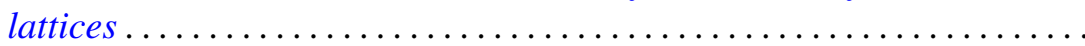

Jan-Erik Björk, Extensions of the maximal ideal space of a function algebra ........................................ 453

Frank Castagna, Sums of automorphisms of a primary abelian group ...... 463

Theodore Seio Chihara, On determinate Hamburger moment problems ..... .

Zeev Ditzian, Convolution transforms whose inversion function has complex

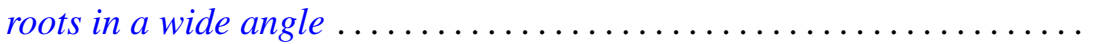

Myron Goldstein, On a paper of Rao .

Velmer B. Headley and Charles Andrew Swanson, Oscillation criteria for

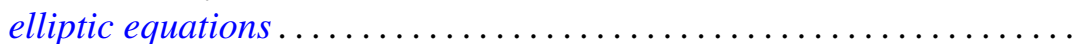

John Willard Heidel, Qualitative behavior of solutions of a third order nonlinear differential equation............................

Alan Carleton Hindmarsh, Pick's conditions and analyticity.............

Bruce Ansgar Jensen and Donald Wright Miller, Commutative semigroups

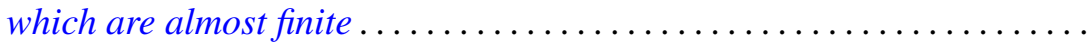

Lynn Clifford Kurtz and Don Harrell Tucker, An extended form of the

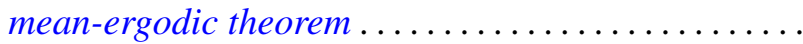

S. P. Lloyd, Feller boundary induced by a transition operator ...

Henry B. Mann, Josephine Mitchell and Lowell Schoenfeld, A new proof of the maximum principle for doubly-harmonic functions ...

Robert Einsohn Mosher, The product formula for the third obstruction ..

Sam Bernard Nadler, Jr., Sequences of contractions and fixed points ...

Eric Albert Nordgren, Invariant subspaces of a direct sum of weighted shifts...

Fred Richman, Thin abelian p-groups ...

Jordan Tobias Rosenbaum, Simultaneous interpolation in $\mathrm{H}_{2}$. II ...

Charles Thomas Scarborough, Minimal Urysohn spaces .

Malcolm Jay Sherman, Disjoint invariant subspaces..... .

Joel John Westman, Harmonic analysis on groupoids....

621

William Jennings Wickless, Quasi-isomorphism and TFM

Minoru Hasegawa, Correction to "On the convergence of resolvents of operators" 